\title{
Desafios e Potencialidades de um Curso on-line sobre Drogas
} Challenges and Potentials of an Online Course on Drugs

\section{Francisco José Figueiredo Coelho*1}

\section{Simone Monteiro²}

1,2 Laboratório de Educação em

Ambiente e Saúde (LEAS)/ Instituto

Oswaldo Cruz (IOC)/ Fiocruz.

Pavilhão Lauro Travassos, sala 49,

Av. Brasil 4365, CEP 21.045-900,

Rio de Janeiro, RJ, Brasil.

*educacaosobredrogas@gmail.com

\section{Resumo}

O campo de formação de professores na educação básica desenvolveu-se muito nas últimas décadas, atestada pela produção científica sobre o tema. Todavia, ainda persistem lacunas na formação do profissional docente, sobretudo acerca de práticas preventivas sobre drogas. A oferta de formação continuada on-line sobre o assunto é uma possibilidade flexível que atinge um maior número de profissionais por meio das plataformas digitais. Partindo dessa premissa, um curso de atualização sobre drogas para professores foi implementado em 2017, a partir da parceria entre a Fiocruz e a Fundação CECIERJ. O curso buscou instrumentalizar os docentes para lidar com o assunto em sala de aula, tendo como enfoque educativo os princípios da Redução de Danos. Por meio das postagens nos fóruns temáticos e dos questionários respondidos pelos cursistas foi possível identificar diferentes potencialidades e desafios da formação, como a gerência do tempo de estudos frente às demandas profissionais e da vida cotidiana. A condução do curso por uma tutoria acolhedora e dialógica favoreceu a construção de espaços de diálogo e aprendizagem ao longo da formação, bem como a troca de experiências entre os cursistas e a promoção de olhares mais compreensivos acerca do tema.

Palavras-chave:Formaçãoon-linesobredrogas. Reduçãodedanos. Formação continuada de professores. Dificuldades na EaD. Potencialidades da EaD. v9i1.742. 


\section{Challenges and Potentials of an Online Course on Drugs}

\section{Abstract}

The field of teacher preparation in elementary education has developed extensively in the last decades, attested by academic research on the subject. However, there are still gaps in teacher training, especially regarding preventive drug practices. Offering an online continuing education on the subject is a flexible option that reaches a greater number of professionals through virtual platforms. Based on this premise, a course on drugs awareness for teachers was implemented in 2017 through a partnership between Fiocruz and the CECIERJ Foundation. The course aimed to prepare teachers to deal with the subject in the classroom, having as educational approach the principles of Harm Reduction. Through postings in the discussion forums and questionnaires completed by the participants, it was possible to identify challenges and potentials of the training, such as time management between study and professional and daily life demands. The friendly and interactive course approach, allowed the creation of spaces for dialogue and learning throughout the training, as well as the exchange of experiences among the participants and the promotion of more comprehensive views on the theme.

Keywords: Online training on drugs. Harm reduction. Teacher preparation. Challenges and potentials in distance education.

\section{Introdução}

Ainda que haja lacunas na formação do docente da educação básica, estudos apontam que o campo de formação de professores desenvolveu-se muito nas últimas décadas e trouxe benefícios relevantes (Gatti, 2014; Monteiro \& Bizzo, 2015; Nóvoa, 2017). Como destacado pela literatura, à medida que o professor explora e (re)conhece sua prática, a formação continuada se torna parte essencial da vida profissional, possibilitando a correção de falhas e atualizações, em face da constante evolução do conhecimento. Ademais, tem o potencial de permitir o acesso a múltiplas ferramentas colaborativas que estimulem a reflexão, que incluem os recursos digitais, cada vez mais utilizados na formação docente (Teixeira \& Almeida, 2015; Coelho \& Monteiro, 2018). O crescimento da EaD como forma de educação profissional continuada entre professores ilustra essa tendência (Almeida, Iannone \& Vilarinhos, 2012; Oliveira, 2014; Coelho \& Monteiro, 2017).

Na modalidade de ensino não presencial, o professor pode realizar formações diversas de forma assíncrona para se atualizar sobre assuntos que permeiam a realidade dos jovens e impactam na saúde e qualidade de vida dos estudantes. Nesse cenário, questões que envolvem a saúde física, mental e social dos adolescentes devem ser abordadas na escola. Isso cria uma demanda de temas transversais sobre saúde (Brasil, 1998) que a escola não tem dado conta de abarcar, como é o caso do consumo abusivo de drogas.

De modo geral, podemos dizer que as abordagens educativas sobre o uso de drogas apontam para duas vertentes contrastantes. Uma centrada na guerra às drogas, que tende a preconizar práticas de amedrontamento e abstenção (proibicionismo), e outra definida pela perspectiva de Redução de Danos (RD), cujo foco é minimizar os danos do consumo de drogas. Segundo Ribeiro (2013), a abordagem da RD leva em conta a diversidade de substâncias e seus usos e as particularidades sociais, culturais e psicológicas dos usuários, possibilitando uma análise das vulnerabilidades associadas ao uso de drogas. Em con- 
traste com o enfoque proibicionista, a RD funda-se nos princípios de pluralidade democrática, exercício da cidadania e respeito aos direitos humanos e de saúde. Desse modo, preconiza que o usuário de drogas deve ser protagonista das reivindicações e cor-responsável pela implementação das modificações para a melhoria de sua vida pessoal e relacional (Ribeiro, 2013; Adade \& Monteiro, 2014; Coelho \& Monteiro, 2017; 2018).

Estudos nacionais têm apontado as dificuldades dos professores da educação básica para inserir o tema drogas nas escolas (Araldi et al., 2010; Adade \& Monteiro, 2014). O despreparo do docente para desenvolver ações educativas foi também assinalado num estudo com professores de escolas públicas do Quênia (King'Endo, 2015). Segundo a autora, cerca de 60\% dos docentes convidam outros profissionais para esse diálogo, por não saberem lidar com o assunto; os demais tendem a suspender os alunos das aulas ou indicar outro profissional para aconselhamento.

As dificuldades para abordar o uso de drogas nas escolas guarda relação com a escassez de programas de formação continuada sobre o tema. Embora seja estimulada pela Lei 11.343 (Brasil, 2006), apenas dois programas a distância, de âmbito nacional, assumiram ações contínuas de larga escala, a fim de preparar profissionais nessa temática. Ambos foram patrocinados pela Secretaria Nacional de Políticas sobre Drogas do Ministério da Justiça (SENAD/MJ). Um deles, denominado SUPERA (Sistema para Detecção do Uso abusivo e dependência de substâncias Psicoativas: Encaminhamento, Intervenção breve, Reinserção social e Acompanhamento), é oferecido gratuitamente por meio da parceria com universidades públicas de São Paulo, mas não contempla exclusivamente profissionais de ensino. O outro foi oferecido por mais de uma década pelo Programa de Estudos e Atenção às Dependências Químicas (PRODEQUI) da Universidade Federal de Brasília (UnB), tendo ocorrido em seis edições para professores da rede pública de ensino em diferentes estados brasileiros (SUDBRACK et al., 2015; SOUZA; CONCEIÇÃO; SUDBRACK, 2018).

Conceição et al. (2015) e Coelho \& Monteiro (2018) comungam do potencial da EaD em abarcar um número extenso de profissionais que, se preparados, podem desenvolver ações educativas articuladas à realidade sociocultural de onde trabalham. Nesse sentido, formações on-line sobre drogas se revelam como ferramentas passíveis de mobilização social, favorecendo a inserção e reflexão do assunto drogas em unidades de ensino de vários estados brasileiros. Diante de tal contexto, a formação dos professores em exercício se configura como condição sine qua non para que os profissionais de ensino experimentem olhares mais dialógicos e menos excludentes acerca da temática drogas, buscando conhecer em plenitude os estudantes e ampliando debates participativos que ofereçam poder de voz aos sujeitos (Cahill et al., 2014; Coelho, Tamiasso-Martinhon \& Porto, 2016). Quer dizer, a EaD pode se configurar como uma aposta educativa viável em função do seu alcance e da disponibilidade de recursos tecnológicos na atualidade.

Em se tratando de Formações on-line para professores, Coelho e Monteiro (2017) enfatizam a importância da capilarização desses cursos em diferentes redes e sistemas de ensino básico, atingindo professores de distintas regiões geográficas. Experiências do primeiro autor desse artigo com professores da rede pública de ensino no estado do Rio de Janeiro confirmam a importância de estimular formações a distância sobre educação e drogas, por meio da oferta gratuita e do estímulo das Secretarias estaduais e municipais de educação.

Tendo por base os argumentos acerca da carência de formações sobre educação e drogas para profissionais da área do ensino, tomamos a iniciativa de desenvolver um curso totalmente on-line sobre drogas no ano de 2017, fruto da parceria entre a Fundação CECIERJ e a Fundação Oswaldo Cruz, por meio do Laboratório de Educação em Ambiente e Saúde (LEAS) do Instituto Oswaldo Cruz. O curso teve como objetivo esclarecer e desmistificar o tema com professores regentes da educação básica do Estado do Rio de Janeiro, instrumentalizando-os para desenvolver espaços de diálogo e aprendizagem sobre drogas com seus estudantes do ensino fundamental e/ou médio. Tal proposta integra a pesquisa de doutoramento do primeiro autor, tendo sido deferida pelo CEP/IOC/Fiocruz (número 1.787.849/2016). Neste artigo, serão discutidos os principais desafios e potencialidades que os cursistas descreveram ao longo da formação e 
como foram mitigados e/ou contornados. Por fim, serão apresentadas possibilidades de melhoramento de formações continuadas preocupadas com a qualidade de vida dos jovens na perspectiva da redução de danos (RD) do uso abusivo de entorpecentes.

\section{Metodologia: da gênese do curso on-line aos instrumentos de coleta de dados}

A formação sobre drogas, intitulada Educação, Drogas e Saúde nas escolas, realizada entre agosto e novembro de 2017, foi organizada em duas etapas e oferecida a todas as áreas de conhecimento. Nas primeiras sete semanas, os cursistas foram estimulados a debater sobre questões reais sobre drogas, centradas na abordagem de RD, e conhecer algumas ferramentas para serem utilizadas em sala de aula para promover debates participativos. Nas demais cinco semanas, o propósito foi orientá-los a construir e implementar atividades sobre educação e drogas em suas escolas. Essa segunda etapa buscou associar a formação teórica e prática docente ao estimular que o professor desenvolvesse ações educativas sobre drogas no espaço de sua escola (em sua aula ou em parceria com outros profissionais), respeitando as especificidades de cada região. Desenvolvidos na plataforma MOODLE, as doze semanas de curso foram centradas em discussões nos fóruns temáticos, visando a estimular espaços mais dialógicos, onde todos pudessem se manifestar e comentar os posicionamentos dos colegas frente às questões propostas pelo curso. O curso foi coordenado e tutorado pelo primeiro autor desse artigo.

Participaram do curso 38 mulheres (77,5\%) e 11 homens (22,5\%); 6 (11,7\%) fizeram apenas a graduação, mas os demais tinham pós-graduação concluída ou em fase de conclusão, sendo a maioria (35) com formação lato sensu. Apenas 10 haviam finalizado a formação sctricto sensu. Dos 49 cursistas, 45 eram professores regentes $(91,84 \%)$, e a maioria era docente da rede pública de ensino $(81,64 \%)$.

Os cursistas souberam da formação por diferentes caminhos: a maioria (24) teve acesso diretamente no site da Fundação CECIERJ (grande parte já havia se inscrito ou realizado algum curso de Atualização na plataforma); onze, em seus ambientes de trabalho, por divulgação de colegas, coordenação ou direção escolar; oito, pelas redes sociais (whatsapp, facebook e afins); cinco, por pesquisas na internet. Um não respondeu. Nota-se que a maioria dos cursistas é frequente em cursos da Fundação CECIERJ, indicando uma disseminação endógena. Isso sinaliza sobre a importância de buscar mecanismos alternativos de divulgação, como contatos com as Metropolitanas Regionais de Educação e Secretarias Municipais de Educação, a fim de que esses espaços sejam divulgadores das formações continuadas.

Como propósito de conhecer a visão dos cursistas em relação à metodologia, conteúdos e participação na formação, foram utilizados os seguintes instrumentos: (1) questionários de perfil; (2) questionários de avaliação do curso; (3) entrevistas semiestruturadas. Os registros dos fóruns temáticos, realizados durante o curso, foram utilizados como fonte complementar de análise. Tendo por base as respostas dos questionários, neste artigo será apresentada a avaliação dos cursistas sobre o conteúdo e a metodologia usados no curso, bem como uma autoavaliação sobre a sua participação na formação on-line.

\section{Resultados e Discussão}

No que tange ao questionário de avaliação do curso, o universo de respondentes foi um pouco menor $(n=34)$. A sistematização dos dados foi organizada em duas discussões, quais sejam: (1) avalição dos conteúdos, metodologia e recursos educativos sugeridos; (2) autoavaliação em relação à motivação, empenho e demandas na formação. 


\subsection{Avaliação dos conteúdos, metodologia e recursos educativos sugeridos}

Em relação à avaliação sobre o conteúdo e a metodologia da formação, o cursista deveria optar por um dos seguintes conceitos: MUITO BOM, BOM, REGULAR e INSUFICIENTE, e incluir algum comentário. Os resultados estão representados na figura abaixo.

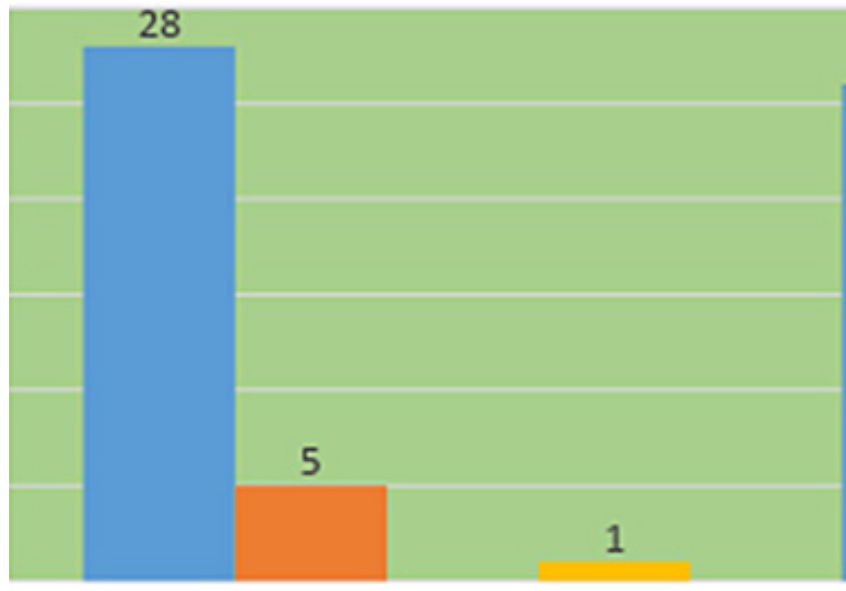

Conteúdo
26

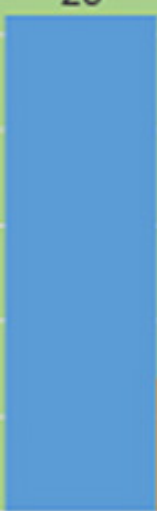

7

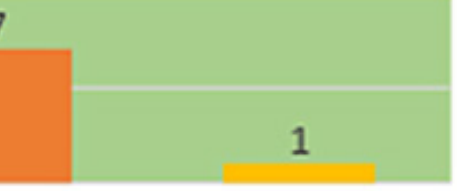

Metodologia

Bom Regular Insatisfatório

Figura 1: Categorias sobre a opinião dos 34 cursistas sobre o conteúdo e a metodologia da formação

Quanto ao conteúdo do curso, a maioria dos cursistas classificou como MUITO BOM (28 dos 34 professores) e registrou comentários de que as discussões nos fóruns semanais estimularam olhares mais claros e abertos acerca do tema, promovendo uma educação mais humanizadora. Assim, foi possível refletir sobre os mitos e preconceitos em relação ao assunto. Os registros são ilustrativos:

Exposição do tema de forma aberta, quebrando preconceitos, desmistificando conceitos arraigados na própria turma de participantes do curso. (ADRIANALET)

O curso foi de muita importância para criarmos propostas e até mesmo desmistificar o tema e abordá-lo de maneira correta e estratégica, sem punição e proibição, apenas com prevenção educativa e esclarecedora. (GINABIO)

Para a maioria dos respondentes, a formação abordou não apenas questões científicas sobre drogas, mas buscou transversalizar o tema com a realidade social e experiências concretas dos cursistas. A estratégia das indagações utilizada pelo tutor foi bastante citada como uma técnica que tornou os conteúdos do curso mais ricos e "leves", contribuindo para a mediação das discussões e as conectando com os temas abordados nas semanas anteriores. Os depoimentos a seguir esclarecem essa ideia:

O tutor foi excelente, sempre nos motivando a continuar em busca do conhecimento. Sua forma extrovertida fez tudo ficar "leve", e a cada tema apresentado, havia uma preocupação em estabelecer ligação com o tema anterior. Sendo assim, havia uma continuidade dos temas, nada estava "solto", fragmentado. (ROSAPED)

Considero muito bom pelo modo como a proposta foi apresentada e desenvolvida ao longo do curso. Foi dinâmico, reflexivo e propôs a interação entre os participantes e o tutor. (MONICABIO) 
A abordagem pedagógica pareceu ser bem aceita pelos cursistas, estimulando-os a um exercício reflexivo sobre as experiências de seus alunos e a realidade de suas escolas. Para a maioria, os conteúdos foram essenciais e superaram as expectativas. Tal aspecto foi também notado nas postagens do fórum da primeira fase do curso. Cinco alunos consideraram os conteúdos do curso como BOM e comentaram sobre a qualidade da tutoria e das indagações e sabatinas realizadas. Apenas um aluno classificou o conteúdo como INSATISFATÓRIO. Seguem exemplos de depoimentos:

\begin{abstract}
Gostei muito das indagações que o tutor suscitava. (ANABIO)
Além dos conteúdos oferecidos pelo curso, nós, professores cursistas, fomos estimulados a buscar mais conteúdos para os estudos dos temas propostos, para debatermos nos fóruns, e assim criarmos uma reflexão. (LUCASEDF)
\end{abstract}

Com relação à metodologia da formação, 26 dos 34 cursistas declararam o curso como MUITO BOM; sete, como BOM; um, como INSATISFATÓRIO (o mesmo que descreveu os conteúdos como insatisfatórios). Não houve posicionamentos para REGULAR, e dez docentes não justificaram seus comentários. A maioria sinalizou que as estratégias do curso foram bem diferentes daquelas a que estavam acostumados em outras formações, elogiando a proposta de oferecer debates abertos e participativos que produzissem interações entre as pessoas. Os depoimentos são ilustrativos:

Proporcionou a interação e a troca de ideias entre os cursistas, fazendo com que nossas percepções fossem ampliadas perante as observações trazidas pelo grupo. (TAISPED)

As diversas metodologias (vídeos, músicas, fóruns) possibilitaram a eficácia dos objetivos para cada desafio lançado em cada semana. (MONICABIO)

Sobre as críticas e sugestões dos profissionais quanto à metodologia, quatro professores fizeram os seguintes registros: (1) tempo curto para a variedade de assuntos, sugerindo que a formação fosse mais longa; (2) pouco entrosamento nos fóruns; (3) desconforto para debater algumas questões centradas em construções pessoais; (4) por vezes, os fóruns se configuraram mais como espaços de "achismos" (aspas de um cursista) que, propriamente, de conteúdos sobre drogas.

Em relação aos recursos educativos sugeridos pelo curso, grande parte declarou que os materiais educativos (vídeos, charges, músicas, situações-problemas, textos e afins) favoreceram que o tema pudesse ser abordado ou mais bem desenvolvido em suas práticas docentes. Nenhum professor respondeu "não" à questão, o que sugere perspectivas de aplicação de alguns dos recursos ofertados em suas aulas ou projetos pedagógicos. Cabe lembrar que cinco professores cursistas não comentaram suas respostas. A seguir, exemplos que caracterizam a aceitação de tais recursos:

Sim. Todos os recursos sugeridos são úteis como apoio às aulas, porque demonstram a rotina diária dos professores em suas práticas educativas diárias. (LUCIALET)

Me surpreendi com a diversidade de estratégias educacionais que podem ser empregadas para se trabalhar o tema drogas. (SUZIEBIO)

Em se tratando de uma formação totalmente on-line, parte dos cursistas afirmou que a diversidade de materiais beneficia a interação da equipe, estimulando o lúdico e motivando a participação nos fóruns. 
A articulação de diferentes mídias pode facilitar a abordagem do tema, variando não apenas o conteúdo como as ferramentas que fomentam os debates nos fóruns. Isso também foi constatado ao longo do curso (especialmente da 3 a 7 semana). A seguir, alguns relatos:

As aulas ficam mais dinâmicas e interessantes. Os alunos aproveitam mais quando a apresentação é mais trabalhada com métodos atrativos. (CELIABIO)

A aprendizagem ativa, envolvendo os vários sentidos, é sempre mais eficaz. (RITAQUI)

\subsection{Autoavaliação em relação à motivação, empenho e demandas na formação}

Quando questionados sobre "como você se sentiu durante a formação?", a maioria se revelou motivada, mas cerca de um terço (dez) revelou alguma dificuldade que os impediu de atingir maior empenho. Dentre os alunos que se declararam motivados, as justificativas mais comuns foram (1) o pleno acompanhamento do professor tutor ao longo do curso; (2) a qualidade dos conteúdos e a metodologia da proposta formativa. As falas abaixo são ilustrativas:

Gostei muito, mas tive dificuldade em acompanhar o ritmo com a frequência que eu gostaria. São muitos alunos e não consegui ler todas as postagens, o que tenho certeza que teria contribuído em algo para mim. (ELENBIO)

Senti-me motivada ao longo do curso. Tive problemas pessoais de saúde, de ordem profissional e acadêmica. Todavia, mesmo sem estar na plataforma interagindo, as propostas do curso me acompanhavam durante toda a semana. Foi muito animador. (MONICABIO)

Apenas um cursista não respondeu à questão, e um não se sentiu motivado; (o mesmo que afirmou não ter ficado satisfeito com os conteúdos e a metodologia do curso). Seu depoimento - "Não sou afeito a blá-blá -blá" (JUCAHIS) - sugere que a proposta de construção colaborativa nos fóruns não o deixava confortável.

Em relação à pergunta sobre as dificuldades para acompanhar o curso na modalidade on-line, dos 34 professores respondentes, praticamente a metade revelou não ter dificuldade durante a formação. Nove registraram algum problema ao longo do curso, e oito indicaram empecilhos parciais. Apenas um aluno não respondeu. Em dois questionários, encontramos justificativas ligadas à 1) inexperiência com a EaD; 2) falta de tempo para os estudos; 3) problemas de saúde, pessoal ou familiar, como ilustram, respectivamente, os relatos a seguir:

(...) Estou me educando para fazer mais cursos ainda online. Acho que o orientador é figura muito importante, pois mesmo a distância ele conseguiu nos deixar sempre próximos no que diz respeito à participação dos trabaIhos. Ele se mostrava sempre atento às questões. (CELIABIO)

Tive dificuldades que considero particulares, como comentei acima, e não como componente da proposta do curso. O tempo para o desenvolvimento das tarefas e interações foi bem dividido. (MONICABIO)

Ainda em relação às dificuldades, cabe ressaltar o relato sobre os problemas de conexão da rede (LURDESGEO - "Internet caindo em vários momentos"), limitação sinalizada pela literatura ao considerar 
que as formações on-line sobre drogas demandam suporte tecnológico e inclusão digital (CONCEIÇÃO \& SUDBRACK, 2015; COELHO \& MONTEIRO, 2017).

Como exemplificado anteriormente, foi possível identificar justificativas sobre a falta de organização temporal. Tal dado aponta que a falta de planejamento dos estudos na modalidade on-line pode comprometer a participação, mesmo quando há aprovação quanto ao conteúdo e abordagem metodológica do curso. Os trabalhos de Netto, Guidotti e Santos (2012), Coelho (2014) e Barros (2017) já sinalizaram para essa dificuldade no âmbito da EaD. Este despreparo dos cursistas na gestão de tempo de estudos nos dão pistas para compreender os casos de abandono que ocorreram ao longo da formação.

Abarcando as respostas sobre a avaliação do próprio desempenho no curso, dos 34 cursistas, apenas nove se consideraram plenamente PARTICIPATIVOS, enquanto 24 gostariam de ter participado mais da formação. Um aluno se considerou "crítico", ao invés de participativo; o mesmo que condenou a proposta do curso centrada na participação e no trabalho colaborativo e que tinha dificuldade em responder aos enunciados e indagações propostas. Esses dados sugerem que a maioria dos cursistas, embora motivada, teve dificuldades na organização do tempo de estudos e na manipulação das ferramentas tecnológicas. Como já descrito, o problema com a gestão do tempo de estudo impossibilitou o melhor aproveitamento do curso.

Quanto às dificuldades dos temas desenvolvidos ao longo do curso, a maioria (18) não relatou qualquer problema; 9 destacaram alguma dificuldade e 7 não responderam. Para a maioria, os assuntos da formação não foram difíceis, como sugerem os comentários:

Difíceis não e sim desafiadores!!! A cada nova semana um tema para desafiar a nossa capacidade de pensar e buscar novos conhecimentos. (MONICABIO)

Não. Estes temas estarão sempre em pauta pois o ambiente escolar é o reflexo dos problemas sociais que vivemos. (...) Educação e saúde caminham juntas neste processo de formação de nossos jovens. (LUCASEDF)

Cabe ressaltar que as dificuldades descritas pelos 9 cursistas foram associadas a outros fatores, quais sejam: despreparo para lidar com o tema (5); definição e conceito de RD (2); encontrar músicas associadas ao tema do curso (1) e implementação do projeto de intervenção na escola (1). Em suma, o despreparo para lidar com o assunto drogas foi a principal dificuldade encontrada pelos cursistas, característica igualmente assinalada nos trabalhos de Ferreira et al. (2010), Adade e Monteiro (2014) e Araldi et al. (2012). Nesse estudo, o que chamamos de despreparo foi relacionado especificamente à falta de domínio sobre o assunto e à delicadeza do tema, frente aos tabus, conforme indicam os depoimentos:

No início achei complexo... Envolve vários aspectos, sociais, culturais, legais, educacionais e envolvem danos à saúde...Não tinha ideia do que fazer.... não me sentia preparada. (VITORIAQUI)

As drogas nos acompanham há tempos!; Proibir ou reduzir danos à saúde? Você decide!; Mais ou menos mal?; A música e a imagem como ferramentas educativas sobre drogas. Porque eu nunca tinha pensado em abordar esse assunto em minhas aulas. (MARTAMAT)

Quando questionados sobre os temas mais interessantes, dos 34 cursistas, a maioria (30) considerou todos os temas; 3 cursistas destacaram alguns temas em especial, e um não respondeu à questão. 
Sim. Possibilitaram um leque de trabalhos criativos por parte dos participantes. Algumas ideias e propostas de filmes e vídeos, charges que devem ser agregadas na prática educativa sobre drogas por todos que mantiverem o assunto em voga nas escolas. (ADRIANALET)

Muito interessantes. Causaram reflexões e trocas, proporcionando vermos o mesmo tema com vários enfoques. (KATIAEDF)

Quanto aos aspectos que faltaram na formação, 14 cursistas destacaram algum aspecto, e 8 não responderam. Dos 12 que julgaram a formação on-line completa, evidenciam-se os relatos nos questionários:

Olha, eu sempre acho que se pode ter mais informações sobre qualquer assunto, mas acho que dentro da proposta do curso, ele cumpriu a meta. (CELIABIO)

A formação sobre drogas para mim foi excelente. Aprendi muito. A partir desse curso pretendo continuar a desenvolver projetos nesta área. (CLEIDEHIS)

Dentre as repostas dos 14 cursistas que sentiram falta de algum tema, um deles (VITORIAQUI) destacou a falta de tempo para absorver a literatura indicada. Afirmou que apenas teve "equilíbrio" ao se conscientizar de que não teria condições de ler todas as postagens e a bibliografia do curso. Tal relato sugere que existe o desejo de aproveitar os recursos didáticos e pedagógicos oferecidos pelo curso, mas parece não ter ficado claro que a Biblioteca Virtual de Educação sobre Drogas foi construída para ser acervo complementar. A leitura de todos os arquivos disponibilizados seria difícil, tendo em vista as condições de trabalho e a carga horária dos docentes.

A criação de espaços de diálogo sobre drogas durante a formação pareceu permitir que novos temas e assuntos se vinculem ao assunto cerne do fórum. Contudo, algumas postagens eram enormes, como enfatizou MARTAMAT: "Todas as vezes em que respondíamos às questões propostas no fórum, o tutor fazia outros questionamentos, tornando-se muito extensa a participação nos fóruns, fazendo com que os colegas dissertassem muito sobre o assunto, tornando-se cansativo para o leitor". De fato, houve o receio de limitar as discussões e perder o caráter "dialógico" da proposta. É importante lembrar que a formação foi desenhada para ser realizada no formato EaD, cujas discussões são registradas de forma escrita. Para contornar esse problema, em cursos futuros, é possível pensar na possibilidade de limitar o número de palavras das postagens nas configurações da atividade, ferramentas oferecidas pelo MOODLE.

\section{Considerações Finais}

Construído em formato sequencial de três meses ininterruptos, o curso de formação sobre drogas teve o propósito de oferecer uma formação em que o professor não precisasse dispensar tantas horas em frente ao computador - o que seria inatingível frente à longa jornada de trabalho. A partir dos resultados, consideramos que uma das grandes potencialidades e contribuições da formação foi fomentar o "diálogo" e o respeito às diferenças. Por meio dos fóruns temáticos, formulamos indagações para os cursistas, provocando-os para saírem de suas zonas de conforto pedagógicas e sociais.

As respostas dos questionários e as postagens nos fóruns temáticos atestaram que grande parte dos cursistas ficou satisfeita com o conteúdo e a abordagem metodológica da formação. Ademais, consideraram que os recursos educativos oferecidos foram úteis às suas práticas docentes. Os depoimentos também revelaram que os alunos se sentiram confortáveis nas salas virtuais. A aposta na experiência 
concreta dos cursistas, aliada às estratégias de acolhimento e monitoramento pelo tutor e a articulação dos conceitos e conteúdos das aulas anteriores, indicou coerência e pareceu dar maior segurança e motivação para os cursistas. Cabe ressaltar que vários cursistas implementaram ações sobre o tema em suas escolas, como previsto pela formação.

Os achados apontam também para a necessidade de aperfeiçoamento da formação, como orientações, desde o início do curso, sobre o planejamento do tempo de estudo e das intervenções nas escolas. Cabe, por exemplo, sugerir que os cursistas se comuniquem com a Direção e os colegas de trabalho, a fim de elaborar parcerias e agendar o período da execução das ações, ampliando a ação para um projeto maior, não centralizado apenas nas suas aulas, como proposto por alguns professores. Outra opção complementar seria a oferta do curso on-line em ambos os semestres, embora alguns cursistas registrassem que no primeiro semestre seria melhor.

Conquanto tenha sido direcionado a professores em exercício da Educação Básica, recebemos demandas de professores universitários. Julgamos que essa proposta de formação pode igualmente ser útil para docentes de ensino superior e estudantes de cursos de licenciatura que, em breve, estarão nas salas de aula e já enfrentarão a realidade de lidar com o tema e com questões sociais a ele relacionadas. Consideramos que a capilarização da formação on-line sobre drogas auxilia na construção inicial e continuada de professores esclarecidos para novas abordagens dialógicas e democráticas sobre o tema, além de permitir experiências de aprendizagem colaborativa via EaD.

\section{Referências Bibliográficas}

ADADE, M. \& Monteiro, S. (2014). Educação sobre drogas: uma proposta orientada pela redução de danos. Educação e Pesquisa, 4(1), 215-230. Disponível em: http://www.scielo.br/pdf/ep/v40n1/aop1140.pdf

ALNEIDA, M. D., IANNONE, L. R., \& VILARINHOS, M. Educação a distância: oferta, características e tendências dos cursos de licenciatura em Pedagogia. Fundação Victor Civita, 2012 (Relatório).

BARROS, S. B. B. (2017) Simulações realísticas na Educação a distância: uma proposta de disciplina de formação de docentes on-line. Dissertação de Mestrado profissional. Instituto de Bioquímica Médica Leopoldo de Meis.

BRASIL. (1998). Ministério da Educação e do Desporto. Secretaria de Educação Fundamental. Parâmetros curriculares nacionais - terceiro e quarto ciclos do ensino fundamental: Saúde. Disponível em: http://portal.mec.gov.br/seb/arquivos/pdf/saude.pdf

BRASIL. (2006) Lei n. 11.343, de 23 de agosto de 2006. Dispõe sobre o Sistema Nacional de Políticas Públicas sobre Drogas. Disponível em: http://www.planalto.gov.br/ccivil_03/_ato2004-2006/2006/lei/ 111343.htm

COELHO F. J. F. (2014). A gestão do tempo na EaD: do aluno ao tutor. In Coelho, F. J. F.; Velloso, A. (Eds.). Educação a Distância: história, personagens e contextos (pp. 69-77). Curitiba: CRV.

COELHO, F. J. F. \& MONTEIRO, S. (2017). Educação sobre Drogas: Possibilidades da EaD na Formação Continuada de Professores. EaD em FOCO, 7(2). doi: http://dx.doi.org/10.18264/eadf.v7i2.577

CONCEIÇÃO, M. I. G. \& SUDBRACK, M. F. O. (2015). Uma década de prevenção do uso de drogas nas escolas públicas do Brasil. In: SUDBRACK, M. F.; CONCEIÇÃO, M. I. G.; SEIDL, E. M. F.; GUSSI, M. A. (Eds.). A escola em rede para prevenção do uso de drogas no território educativo: Experiência e pesquisa no PRODEQUI/PCL/IP/UnB nos dez anos de formação de educadores de escolas públicas para prevenção do uso de drogas (2004-2014). Campinas: Armazém do Ipê. 
FERREIRA., T. C. D. SANCHES., Z. V D. M., RIBEIRO, L. A., OLIVEIRA, L. G. \& NAPPO, S. A. (2010). Percepções e atitudes de professores de escolas públicas e privadas perante o tema drogas. Interface - Comunic., Saúde, Educ., 14(34), 551-562. doi: http://dx.doi.org/10.1590/S1414-32832010005000007

GATTI, B. A. (2014). A formação inicial de professores para a Educação básica. Revista USP. São Paulo, 100(1), 33-46. Disponível em https://www.revistas.usp.br/revusp/article/viewFile/76164/79909

KING'ENDO, M. (2015). Behavior disorders related to drug abuse among secondary school students in Kenya. Journal of Education and Practice, 6(19), 170-178. Disponível em http://files.eric.ed.gov/ fulltext/EJ1079526.pdf

NETTO, C., GUIDOTTI, V. \& SANTOS, P. K. (2012). A Evasão na EaD: investigando causas, propondo estratégias. In: II Conferencia Latinoamericana sobre el Abandono de la Educación Superior (II CLABES), Porto Alegre. Disponível em http://www.alfaguia.org/wwwalfa/images/ponencias/clabesII/LT 1/ ponencia_completa_26.pdf

NÓVOA, A. (2017). Firmar a posição como professor, afirmar a profissão docente. Cadernos de Pesquisa, 47(166), 1106-1133. doi:http://dx.doi.org/10.1590/198053144843

OLIVEIRA, F. S. (2014). EaD E FORMAÇÃO DOCENTE: possibilidade de crescimento pessoal, intelectual e individual In: Coelho, F. J. F., \& VELLOSO, A. (Eds.). Educação a Distância: história, personagens e contextos (pp. 99-106). Curitiba: CRV.

RIBEIRO, M. M. (2013). Drogas e redução de danos: os direitos das pessoas que usam drogas. São Paulo: Editora Saraiva, p. 147.

TEIXEIRA, N. F., \& ALMEIDA, P. V. (2015). Formação de Professores na Educação a Distância e a Prática Reflexiva. Revista EaD em foco, 5(3), 1-14, 2015. doi: http://dx.doi.org/10.18264/eadf.v5i3.281 